Ortognatik cerrahide kullanılan titanyum miniplakların söküm prevelansı: Uzun dönem takipli retrospektif çalışma

\section{The prevelance of removal of miniplates used in orthognathic surgery: A retrospective study with long-term follow-up}

\section{Dr. Öğr. Üyesi Seçil Çubuk}

Başkent Üniversitesi, Diş Hekimliği Fakültesi, Ağız, Diş ve Çene Cerrahisi A.D., Ankara

Orcid ID: 0000-0003-2065-7555

\section{Prof. Dr. Burçak Kaya}

Başkent Üniversitesi, Diş Hekimliği Fakültesi, Ortodonti A.D., Ankara

Orcid ID: 0000-0002-7953-3445

\section{Prof. Dr. Burak Bayram}

Başkent Üniversitesi, Diş Hekimliği Fakültesi, Ağız, Diş ve Çene Cerrahisi A.D., Ankara

Orcid ID: 0000-0002-2467-6473

\section{Prof. Dr. Sina Uçkan}

Medipol Üniversitesi, Diş Hekimliği Fakültesi, Ağız, Diş ve Çene Cerrahisi A.D., İstanbul

Orcid ID: 0000-0003-1077-7342

Geliş tarihi: 28 Nisan 2021

Kabul tarihi: 1 Haziran 2021

doi: 10.5505/yeditepe.2022.60352

\section{Yazışma adresi:}

Dr. Öğr. Üyesi Seçil Çubuk

Başkent Üniversitesi Diş Hekimliği Fakültesi,

Ağız, Diş ve Çene Cerrahisi Anabilim Dalı, 82. Sok.

No:26 Ankara, Türkiye

Tel: +903122036868

E-posta: secilcubuk@hotmail.com
ÖZET

Amaç: Bu çalışmanın amacı ortognatik cerrahi uygulanmış hastalarda miniplak ile ilişkili gelişen komplikasyonların uzun dönemli takip sürecince değerlendirilmesidir.

Materyal ve Metod: Araştırmaya 2004-2017 yılları arasında ortognatik cerrahi uygulanmış hastalar dahil edilmiştir. Miniplak söküm nedeni, miniplak sökümü uygulanan bölge, ortognatik cerrahi ile miniplak söküm işlemi arasında geçen süre ve miniplak sökümü sonrasında bulgu ve semptomlarda iyileşme durumu değerlendirilmiştir.

Bulgular: Araştırmaya dahil edilen 70 hastanın $11^{\prime}$ inde $(\% 15,7)$ toplam 19 adet miniplak söküm işlemi uygulanmıştır. Ortalama takip süresi 7,65+2,81 (3,5-15,3 yıl) yıl olup; ortognatik cerrahi ile miniplak çıkartılma işlemleri arasında geçen süre ortalama 1.52 yıldır (4 ay-6 yıl). Miniplak söküm nedenleri enfeksiyon $(\% 45,5)$, soğuk hassasiyeti $(\% 18,2)$, miniplağın palpe edilebilir hale gelerek hastada rahatsızlık oluşturması (\%9), miniplağın bulunduğu bölgeye başka bir cerrahi uygulama yapılacak olması $(\% 18,2)$ ve hasta isteği olarak sıralanabilir $(\% 9)$. Toplam 13 adet $(\% 11,6)$ miniplak mandibuladan çıkartılmış; 6 adet $(\% 3,06)$ miniplak ise maksilladan çıkartılmıştır. Çene ucunda miniplak söküm işlemi uygulanmamıştır. Enfeksiyon nedeniyle mandibuladan miniplak sökülme oranının \%69, maksilladan miniplak sökülme oranının ise \%16,6 olduğu görülmüştür $(p<0,05)$. Miniplak bulunan bölgeye uygulanacak başka bir cerrahi işlem nedeniyle maksilladan toplam 3 adet (\%50) miniplak sökülmüş, mandibulada ve çene ucunda ise bu nedenle miniplak söküm işlemi uygulanmamıştır $(p<0,05)$. Sonuç: Kliniğimizde 13 yıllık bir süreçte ortognatik cerrahi uygulanmış hastalarda miniplak söküm prevelansının \%15,7 olduğu görülmüştür. Miniplak ile ilişkili komplikasyonlar ortognatik cerrahiden ortalama 1,5 yıl sonra gelişmiş, postoperatif 5. yıldan sonra miniplaklar ile ilişkili herhangi bir komplikasyon görülmemiştir.

Anahtar kelimeler: Ortognatik cerrahi; osteosentez; miniplak; komplikasyon.

\section{SUMMARY}

Aim: The aim of this study was to evaluate the complications associated with miniplates in patients who underwent orthognathic surgery, in the long-term follow-up period.

Materials and Methods: Patients who underwent orthognathic surgery between 2004-2017 were included in this study. The reason for miniplate removal, the region where miniplate removal was performed, the time between orthognathic surgery and miniplate removal, and the improvement in signs and symptoms after miniplate removal were evaluated.

Results: A total of 19 miniplate removal procedures were performed in 11 (15.7\%) of the 70 patients included in the study. The mean follow-up period was $7.65+2.81$ (3.5-15.3 years) years. The mean time between orthognathic surgery and miniplate removal procedure was 1.52 years. The reasons for miniplate removal were infection (45.5\%), cold sensitivity $(18.2 \%)$, palpable plate $(9 \%)$, planning another surgery to the 
region where the miniplate was located (18.2\%), and patient request $(9 \%)$. A total of $13(11.6 \%)$ miniplates were removed from the mandible; 6 miniplates (3.06\%) were removed from the maxilla. None of the miniplates located on the chin was removed. The rate of miniplate removal from the mandible due to infection was found as $69 \%$, and the rate of miniplate removal from the maxilla due to infection was $16.6 \%$ ( $p<0.05) .3$ miniplates $(50 \%)$ were removed from the maxilla for sinus lifting and rhinoplasty. On the other hand, no miniplate was removed neither from the mandible nor the chin for another surgery $(p<0.05)$.

Conclusion: It was observed that the prevalence of miniplate removal was $15.7 \%$ in patients who underwent orthognathic surgery in our clinic for a period of 13 years. Complications associated with miniplate developed 1.5 years after orthognathic surgery, and no complication was observed in the period 5 years after the operations.

Key words: Orthognathic surgery, osteosynthesis, miniplate, complications.

\section{Giriş}

Maksillofasiyal bölgede uygulanan osteotomilerin fiksasyonunda monokortikal titanyum (Ti) plaklar yaklaşık 50 yıldır kullanılmaktadır. ${ }^{1}$ Yerleştirildikten 3 ay sonra çıkartılması önerilen vitalyum ve paslanmaz çelik plakların aksine, titanyum plakların yüksek biyouyumu ve korozyon resistansı gibi özellikleri sayesinde rutin olarak çıkartılmaları gereksiz bir müdahale olarak kabul edilmektedir. ${ }^{2-4} \mathrm{An}$ cak postoperatif dönemde miniplakla ilişkili gelişen çeşitli komplikasyonlar ve durumlar nedeniyle miniplakların çıkartılması gerekebilmektedir.

Ortognatik cerrahi uygulanmış hastalarda gelişen miniplak ile ilişkili komplikasyonlar ile maksillofasiyal travma cerrahisi uygulanmış hastalarda gelişen miniplak ile ilişkili komplikasyonların farklı gruplar halinde incelenmesi gerekmektedir. ${ }^{5}$ Bunun nedenlerinden biri ortognatik cerrahinin genellikle genç yaştaki sağlıkı hastalara uygulanması; fraktür onarımı yapılan hasta gruplarının ise yaş ve sağlık durumu açısından genellikle homojen olmamasıdır. Ayrıca ortognatik cerrahide intraoral yaklaşım uygulanmakta bu nedenle temiz-kontamine yara yeri oluşturulmaktadır. Bu durumun aksine travmaya bağlı fraktür fiksasyonu uygulanmış hastaları değerlendirirken kutanöz yaklaşım gereksinimi, gecikmiş cerrahi ve enfekte cerrahi bölgesi gibi çok sayıda komplike faktörün göz önünde bulundurulması gerekir.

Literatürde ortognatik cerrahi sonrası miniplaklarla ilişkili komplikasyonların gelişme zamanı ile ilgili farklı veriler bulunmaktadır. ${ }^{4-10} \mathrm{Bu}$ farklılığın oluşmasında olası etken faktörler; cerrahi merkezleri arasında bulunan tedavi yaklaşım farklıığı ve araştırma gruplarının takip sürelerindeki farklııklar olarak sıralanabilir. Örneğin ortognatik cerrahi sonrası miniplak söküm prevalansı ile ilgili yapılan bir çaışmada operasyondan sonraki ilk 6 haftalık süreçte yara yerinde herhangi bir inflamatuar yanıt görülmesi durumunda postoperatif 3. ayda plakların sökümü önerilmiştir. ${ }^{5}$ Ayrıca aynı araştırmada miniplaklar ile ilişkili bir komplikasyon gelişmesi riskine karşı erken müdahale edebilmek amacıyla yara yerlerinin postoperatif dönemde en az 18 ay takip edilmesini önermişlerdir. ${ }^{5}$ Bununla beraber bu konuyla ilgili bir başka çalışmada ortognatik cerrahi uygulanmış ve herhangi bir nedenle miniplak sökümü gerekmiş hastaların yaklaşık olarak \%10'unda miniplağa ilişkin komplikasyonun postoperatif 10. yıldan sonra geliştiği rapor edilmiştir.10 Ayrıca miniplağın açığa çıkması ya da enfeksiyon gibi komplikasyonlarla ilişkili miniplak söküm gereksinimi sürelerinin bifazik olduğu belirtilmiş; hastaların yaklaşık \%14'ünde postoperatif ilk bir yıl içerisinde, yaklaşık \%20'sinde ise postoperatif 5 . yıldan sonra miniplak sökümü uygulandığı bildirilmiştir.10

Ortognatik cerrahi uygulanmış hastalarda Ti miniplak fiksasyon sistemlerinin postoperatif uzun dönemdeki akıbetlerinin daha net bir şekilde ortaya koyulabilmesi bakımından uzun dönem takip süreleri olan araştırmalara intiyaç olduğu görülmektedir. Bu retrospektif kohort çalışmasının amacı 13 yıllık bir süreçte kliniğimizde ortognatik cerrahi uygulanmış hastalarda miniplaklar ile ilişkili gelişen komplikasyonların değerlendirilmesidir.

\section{Bireyler ve Materyal Metod}

Bu çalışma Başkent Üniversitesi Tıp ve Sağlık Bilimleri Araştırma ve Etik Kurulu tarafından onaylanmış (Proje no: D-KA 18/02) ve Başkent Üniversitesi Araştırma Fonunca desteklenmiştir. Araştırmaya dahil edilen bütün hastalar bilgilendirilmiş gönüllü onam formunu imzalamışlardır.

Gözlemsel retrospektif kohort araştırma olarak dizayn edilen çalışmaya 2004-2017 yılları arasında ortognatik cerrahi uygulanan hastalar dâhil edilmiştir. Çalışmaya Başkent Üniversitesi Ağız, Diş ve Çene Cerrahisi bölümünde maksiller osteotomi (LeFort 1 osteotomisi), madibular osteotomi (sagital split ramus osteotomisi) ve genioplasti uygulanmış, elektronik veritabanında hasta verilerinin tamamına erişilebilen hastalar dahil edilmiştir. Demografik bilgiler, sistemik hastalıklar, sigara kullanım durumu, osteotomi türü ve hasta takip süreleri incelenmiştir. Miniplak sökümü yapılan hastalar ile ilgili araştırmamızda değerlendirilen kayıtlar; miniplak söküm nedenini, miniplak sökümü yapılan bölgeyi (maksilla, mandibula), miniplak sökümü ile operasyon arasında geçen süreyi ve söküm işlemi sonrasında bulgu ve semptomlarda gözlenen değişimleri (iyileşme var/yok) içermektedir.

\section{İstatistiksel Analiz}

Araştırma verileri SPSS 22 (IBM Corp., Armonk, New York, USA) programı kullanılarak analiz edilmiştir. Sürekli veriler ortalama + standart sapma olarak, süreksiz veriler yüzdelik oran olarak ifade edilmiştir. Kategorik verilerin analizi için $\chi 2$ testi uygulanmıştır. Frekansı $5^{\prime}$ ten olan değişkenlerin analizi için Fisher's exact testi kullanılmıştır. p değeri- 
nin 0.05 'ten küçük olması istatistiksel olarak anlamlı kabul edilmiştir.

\section{BULGULAR}

Araştırmaya toplam 70 hasta (40 kadın, 30 erkek) dahil edilmiştir. Hastaların yaş ortalaması 23,75+6,37 olup, ortalama takip süresi 7,65+2,81 yıldır (3.5-15.3 yıl). Hastaların \%15,7'sinin takip süresi 5 yıldan kısa süreli, \%60'ının takip süresi 5-10 yıl, \%24,3'ünün takip süresi 10 yıldan fazla sürelidir. Le Fort 1 osteotomisi fiksasyonunda tüm hastalarda 4 adet L plak; sagittal split ramus osteotomisi fiksasyonunda ise tüm hastalarda 2 adet I plak kullanılmıştır (DePuy Synthes, Johnson \& Johnson, Massachusetts, USA). Genioplasti operasyonunda fiksasyon için genioplasti plakları kullanılmıştır (DePuy Synthes, Johnson \& Johnson, Massachusetts, USA). Sigara kullanma hikayesi olan 9 hastanın $(\% 12,8)$ birine miniplak sökümü uygulanmıştır.

Osteotomi dağılımları şu şekildedir:

- Le Fort 1 osteotomisi $(n=5)$

-BSSO $(n=11)$

- Çift çene osteotomisi ( $n=36)$

-Çift çene osteotomisi ve genioplasti $(n=8)$

-BSSO ve genioplasti $(n=5)$

- Le Fort 1 ve genioplasti $(n=2)$

-Genioplasti $(n=3)$

Miniplak çıkartılmasında etken olan faktörler Tablo 1'de ve miniplak sökümünün osteotomi bölgelerine göre dağııımları Tablo 2'de gösterilmiştir.

Tablo 1. Miniplak söküm uygulamasında etken olan faktörler ve bölgelere göre dağııımı

\begin{tabular}{|c|c|c|c|c|c|c|}
\hline $\begin{array}{l}\text { Plak } \\
\text { Çıartılma } \\
\text { Nedeni }\end{array}$ & $\begin{array}{l}\text { Hasta } \\
\text { Sayısı } \\
n=70\end{array}$ & $\begin{array}{l}\text { Plak } \\
\text { Sayıs1 } \\
\text { n=330 }\end{array}$ & $\begin{array}{l}\text { Maksilla } \\
\text { n= }\end{array}$ & $\begin{array}{l}\text { Mandibula } \\
\mathrm{n}=\end{array}$ & $\begin{array}{l}\text { Çene } \\
\text { Ucu } \\
n=\end{array}$ & $\begin{array}{l}P \\
\text { değeri }\end{array}$ \\
\hline Enfeksiyon & $5(\% 45.5)$ & $10(\% 52.6)$ & $1(\% 16.6)$ & $9(\% 69)$ & - & 0.049 \\
\hline $\begin{array}{l}\text { Soğuk } \\
\text { hassasiyeti }\end{array}$ & $2(\% 18.2)$ & $2(\% 10.5)$ & $1(\% 16.6)$ & $1(\% 7.7)$ & - & 1 \\
\hline $\begin{array}{l}\text { Mukoza } \\
\text { altından } \\
\text { hissedilmesi }\end{array}$ & $1(\% 9)$ & $2(\% 10.5)$ & $1(\% 16.6)$ & $1(\% 7.7)$ & - & 1 \\
\hline Hasta isteği & $1(\% 9)$ & $2(\% 10.5)$ & 0 & $2(\% 15.4)$ & - & 0.5 \\
\hline $\begin{array}{l}\text { Diğer cerrahi } \\
\text { uygulamalar }\end{array}$ & $2(\% 18.2)$ & $3(\% 15.8)$ & $3(\% 50)$ & 0 & - & 0,02 \\
\hline Toplam & $11(\% 15.7)$ & $19(\% 5.7)$ & $6(\% 3.1)$ & $13(\% 13 . .1)$ & 0 & \\
\hline
\end{tabular}

Tablo 2. Miniplak söküm uygulamasının osteotomi bölgelerine göre dağılımı

\begin{tabular}{|l|c|c|c|}
\hline $\begin{array}{l}\text { Osteotomi } \\
\text { Bölgesi }\end{array}$ & $\begin{array}{c}\text { Plakların } \\
\text { Muhafazası }\end{array}$ & Plak Sökümüi & Toplam \\
\hline Maksilla & $198(\% 97)$ & $6(\% 3)$ & 204 \\
\hline Mandibula & $99(\% 82.5)$ & $13(\% 10.8) *$ & 120 \\
\hline Cene ucu & $18(\% 100)$ & 0 & 18 \\
\hline Toplam & $323(\% 94.5)$ & $19(\% 5.5)$ & 342 \\
\hline
\end{tabular}

*Mandibuladan miniplak söküm oranı maksilladan ve çene ucundan yapılan miniplak söküm oranından istatistiksel olarak anlamlı derecede yüksek bulundu $(p=0,01)$

Miniplak çıkartılma endikasyonları şu şekilde kategorize edilmiştir;

-Enfeksiyon: Miniplakla ilişkili şişlik, progresif ağrı, purulan akıntı, yara yerinde dehisens oluşumu.

-Miniplak bölgesinde soğuk hassasiyeti

-Miniplak ya da vidaların palpe edilebilir hale gelerek has- tada rahatsızlık oluşturması

-Hasta isteği

-Miniplak varlığının bölgeye uygulanacak cerrahi işlemlere engel oluşturması

Kliniğimizde takip edilen hastalarda standart uygulama olarak ortognatik cerrahiyi takiben ilk 16 haftalık dönemde enfeksiyon bulgularının görülmesi durumunda antibiyotik tedavisi, yara yeri debridmanı ve püy drenajı uygulamaları ile hasta takibi yapılmıştır. Semptomların devam etmesi durumunda postoperatif 16 . haftadan sonra miniplak sökümü yapılmıştır. Miniplak sökümü yapılan 11 hastadan (\%15,7, 6 kadın ve 5 erkek) toplam 19 adet miniplak $(\% 5,7)$ sökülmüştür. Hastaların yaş ortalaması $26+4,89$ olup, ortognatik cerrahi ile miniplak çıkartılma işlemleri arasında geçen süre ortalama 1.52 yıldır (4 ay-6 yıl). Miniplak sökümü yapılan 11 hastadan 9'unda (\%82) miniplak söküm işlemi ortognatik cerrahiyi takiben ilk 1 yıl içerisinde olmuştur. Bu hastalarda toplam 15 adet miniplak sökülmüş olup, bu plaklar araştırmamızda sökülen tüm miniplakların \%79'udur. Miniplak sökümü yapılan hastaların tamamında semptomlarda iyileşme görülmüştür.

Maksillaya uygulanan toplam miniplakların \%3,1'i sökülmüş, mandibulaya uygulanan toplam miniplakların ise \%13,1'i sökülmüştür. Çene ucunda ise miniplak söküm işlemi uygulanmamıştır. Mandibulaya uygulanan miniplakların sökülme oranı maksilla ve çene ucuna uygulanan miniplak söküm oranından istatistiksel olarak anlamlı bir şekilde yüksektir. $(p=0,01)$ (Tablo 2 ).

Miniplak sökümü gereksiniminde rol oynayan etkenlerin başında miniplak ile ilişkili enfeksiyon bulgularının görülmesi gelmiştir (Resim 1-2).

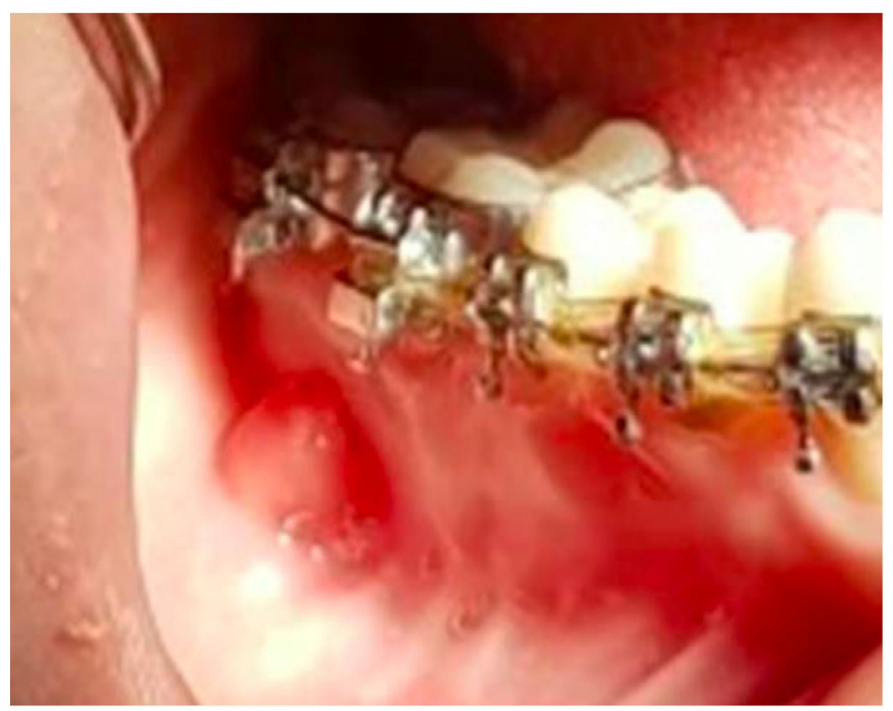

Resim 1. 21 yaşındaki kadın hastada sagital split ramus osteotomisinden 1 yıl sonra mandibulada abse ve fistül oluşumu ile seyreden enfeksiyon tablosu gelişmiştir. 


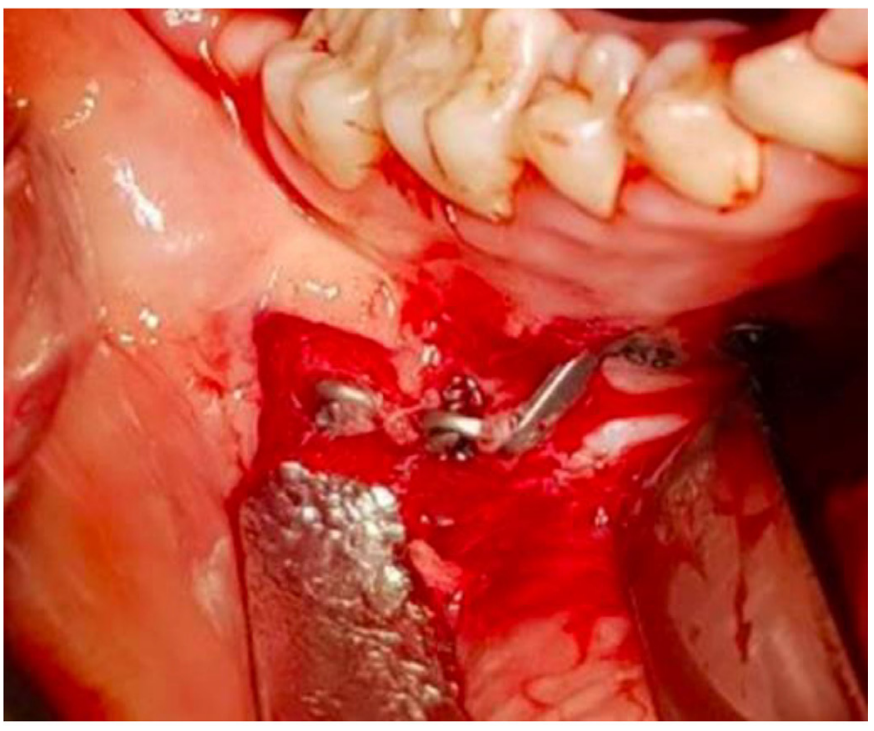

Resim 2. Miniplak ve vida sökümü yapılırken osteotomi hattının distalinde ye alan vidanın etrafındaki kemikte rezorpsiyon ve miniplak stabilitesinde azalma tespit edilmiştir.

Miniplak sökümü yapılmış toplam 11 hastadan 5'inde (\%45) 10 adet miniplak $(\% 52,6)$ enfeksiyon nedeniyle çוkartılmıştır. Diğer etken faktörler ise soğuk hassasiyeti (n:2, \%10,5), hastanın miniplağı mukoza altında hissetmesi nedeniyle duyduğu rahatsızlık (n:2, \%10,5), hasta tarafından miniplağın çıkartılmasının istenmesi $(n: 2, \% 10,5)$ ve miniplakların sinüs lifting veya rinoplasti osteotomileri alanında bulunması (n:3, \%15,8) olarak sıralanabilir. (Tablo 1) TARTIŞMA

Titanyum miniplaklar maksillofasiyal travma ve ortognatik cerrahide sıklıkla kullanımaktadır. Miniplaklarla ilişkili komplikasyonlar nadiren gelişmekte ve ikinci bir cerrahi işlemle miniplakların çıkartılması gerekmektedir. ${ }^{4-10} \mathrm{Bu}$ komplikasyonların başında enfeksiyon gelmektedir.

Jhass ve ark. ${ }^{9}$ enfeksiyon gelişimi nedeniyle çıkarttıkları miniplakları elektron mikroskobunda incelemişler ve bu plakların \%75'inde çeşitli derecelerde biyofilm oluşumu olduğunu bildirmişlerdir. Ayrıca bu araştırmacılar miniplaklar ile ilişkili gelişen enfeksiyon tablosuyla biyofilm ilișkili enfeksiyonun klinik özelliklerinden olan enfeksiyonun lokalize seyretmesi, antibiyotik tedavisine genellikle direnç göstermesi ve semptomların cerrahi işlemden yııllar sonra ortaya çıkabilmesi gibi durumların uyumlu olduğunu belirtmişlerdir. ${ }^{9}$

Literatürde ortalama takip süreleri 23 ay ile 4.6 yıl arasında değişen farklı araştırmalarda miniplak sökümü ile cerrahi işlem arasında geçen ortalama sürenin 5.5 ay ile 6 yıl aralığında olduğu bildirilmiştir. ${ }^{5-8,11}$ Bizim çalışmamızda ise ortognatik cerrahi sonrası takip süresinin 7.65 yıl ile literatürdeki diğer çalışmaların takip süreleriyle kıyaslandığında daha uzun olduğu ve ortognatik cerrahi ile miniplak sökümü arasında geçen ortalama sürenin 1.52 yıl olduğu görülmüştür. Bu bulgunun literatürdeki çalışmaların bir kısmı ile uyumlu olduğu, bir kısmı ile ise farklılık gösterdiği görülmüştür. 5,6,9,12 Çalışmamızda miniplakların büyük bir çoğunluğu postoperatif ilk bir yıllık süreçte sökülmüş ve sadece \%21,1'i postoperatif 1. yıldan sonra sökülmüştür. Bizim çalışma grubumuzda ortognatik cerrahi uygulanan hastalarda postoperatif 5. yıldan sonra miniplaklarla ilişkili olarak gelişen herhangi bir komplikasyon görülmemiştir. Widar ve $a^{4}{ }^{4}$ ortognatik cerrahi sonrası miniplak sökümünde rol oynayan risk faktörlerini değerlendirmişlerdir. Miniplaklarla ilişkili enfeksiyon gelişiminde rol oynayan majör risk faktörlerini; hastaların sigara kullanımı, mandibula cerrahisi ve mandibulaya yerleştirilen miniplak sayısı olarak bildirmişlerdir. ${ }^{4}$ Benzer olarak bizim çalışmamızda da mandibuladan çıkartılan miniplak oranı maksilladan çıkartılan miniplak oranından anlamlı bir şekilde yüksek bulunmuştur. Bu farkııı̆ın oluşmasında çenelerin fonksiyonu sırasında mandibula korpusunda fleksiyon ve hareketliliğe neden olabilecek mandibulaya özgü anatomik özelliklerin rol oynadığına dair görüşler bulunmaktadır. ${ }^{4}$

Sagital split ramus osteotomisi fiksasyonunda kullanılan bikortikal vidalar miniplaklarınkine benzer derecelerde iskeletsel stabilite sağlamaktadır.11 Bikortikal vidaların yüzey alanı oldukça küçüktür dolayısıyla miniplaklarla kıyaslandığında bikortikal vida yüzeyinde daha az oranda bakteri tutulumu olmaktadır. ${ }^{13}$ Literatürde bikortikal vidalarla ilişkili enfeksiyon gelişimi ve diğer komplikasyonların değerlendirildiği çalışma sonuçları bikortikal vidaların söküm oranlarının $(\% 2,8-\% 7,2)$ miniplak söküm oranlarından oldukça düşük olduğunu göstermektedir. ${ }^{13-16}$ Bu verilere dayanarak klinisyenlerin sagital split ramus osteotomisi fiksasyonunda miniplak ve bikortikal vida yerleştirme tekniklerinden birini tercih etme aşamasında, bu iki teknik ile ilişkili postoperatif komplikasyon oranlarındaki farklılıkları da göz önünde bulundurmaları gerektiği vurgulanabilir.

Bizim çalışmamıza dahil edilen hastaların \%12,8'inde sigara kullanma hikayesi mevcuttur ve bu hastalardan sadece birinde miniplak sökümü gerekmiştir. Bu hastada miniplaklar mukoza altından hasta tarafından hissedilebilir hale gelmesi nedeniyle sökülmüştür. Bu nedenle çalışmamıza ait mevcut veriler kullanılarak sigara kullanımının miniplaklar ile ilişkili komplikasyonlara etkisini değerlendirmek mümkün olmamıştır.

Yumuşak dokuda yaşlanmaya bağlı oluşan değişiklikler nedeniyle osteosentez materyalleri yumuşak doku altında daha belirgin hale gelebilir ve hastalarda rahatsızlık oluşturabilir. Bu tür komplikasyonlar genellikle ameliyattan 1-2 dekat sonra ortaya çıkmaktadır. ${ }^{6}$ Literatürdeki çaıışmaların çoğunun takip süresi bu komplikasyonu değerlendirebilecek kadar uzun değildir. Bizim çalışmamızda bir hastada mandibula ve maksilladaki birer adet miniplak postoperatif 16 . ay ve 4 . yılda mukoza altından hissedilebilir hale geldiği için sökülmüştür. Postoperatif takip süresinin 10 yıldan fazla olduğu 17 hastanın hiçbirinde böyle bir komplikasyona rastlanılmamıştır. Miniplakların yaşlanma ile beraber mukoza altından hissedilebilir hale gelmesi ile ilgili daha iyi bir değerlendirmeyi ise takip süresi 10 
yıldan fazla olan daha geniş vaka sayılı ileri araştırmalar ile yapmak mümkündür.

Kuhlefert ve ark. ${ }^{7} 4$ hastada soğuk hassasiyeti nedeniyle miniplak sökümü yaptıklarını ve bu hastaların yaş ortalamasının (40.1 yıl) diğer komplikasyonların geliştiği grupların yaş ortalamasından anlamlı bir şekilde yüksek olduğunu bildirmişlerdir.7 Bizim çalışma grubumuzda ise soğuk hassasiyetinin görüldüğü 2 hastanın yaş ortalaması 25 olup yukarıda bahsedilen çalışma sonuçlarıyla bu bakımdan farklılık göstermektedir.

Titanyum miniplakların söküm nedenlerinden biri hastaların vücutlarında yabancı bir cisim taşımak istememesidir. Titanyum inert, korozyona dirençli ve biyouyumlu bir materyal olarak bilinmesine rağmen dental implant uygulamaları yapılan bazı hayvan çalışmalarında uzun dönemde böbrekten, karaciğerden, bağırsaktan ve dalaktan elde edilen doku örneklerinde titanyum izlerine rastlanılması titanyumun korozyon rezistansı ile ilgili şüpheye neden olmuştur. ${ }^{17,18}$ Bizim çalışma grubumuzda bir hasta vücuda yerleştirilen metal materyaller ile ilgili bu tür risklerden duyduğu endişe nedeniyle miniplaklarının çıkartımasını istemiştir. Bu hastanın ortognatik cerrahiden 6 ay sonra mandibulada bulunan miniplakları çıkartıımışıı.

Ortognatik cerrahide yerleştirilen miniplaklar konumları ve pozisyonları nedeniyle diğer cerrahi uygulamalarına engel olabilmektedir. İkincil cerrahi işlemler nedeniyle miniplak sökümü yapıldığı bildirilen vaka sayısı literatürde oldukça kısıtıdır. ${ }^{6}$ Falter ve ark. ${ }^{6}$ dental implant yerleştirmeden önce miniplak sökümü yaptıkları vaka oranını \%1 $(n=2)$ olarak bildirmişlerdir. Bizim çalışmamızda bir hastada sinüs ogmentasyonu uygulaması sırasında 1 adet miniplak sökümü yapılmıştır. Bir başka hastada ise rinoplasti işleminden önce apertura piriformisin lateralinde bulunan miniplakların söküm gereksinimi doğmuştur. Bu veriler doğrultusunda ortognatik cerrahi sonrası maksilla ve mandibulaya başka bir cerrahi müdahale daha planlanan hastalarda miniplak söküm işleminin gerekebileceği ile ilgili bilgilendirmenin yapılması önerilebilir.

\section{SONUÇ}

Kliniğimizde 13 yıllık bir süreçte ortognatik cerrahi uygulanan hastaların \%15,7'sinde miniplak sökümü uygulanmıştır. Miniplakların yaklaşık \%80'inin operasyondan sonraki ilk 1 yıl içerisinde sökülmesi gerekmiştir. Postoperatif 5. yıldan sonraki dönemde miniplak ile ilişkili bir komplikasyon görülmemiştir. Miniplak ile ilişkili en sık gelişen komplikasyon enfeksiyon olmuş ve mandibuladan enfeksiyon nedeniyle miniplak söküm oranı maksilladan enfeksiyon nedeniyle miniplak söküm oranından anlamlı derecede yüksek bulunmuştur. Maksilladan miniplak sökümünde rol oynayan en büyük etken ise miniplağın bulunduğu bölgede uygulanan diğer cerrahi müdahaleler olmuştur.

\section{KAYNAKLAR}

1.Michelet FX, Deymes J, Dessus B.Osteosynthesis with miniaturized screwed plates in maxillo-facial surgery. J Maxillofac Surg 1973; 1: 79-84.

2.Moberg LE, Nordenram A, Kjellman O. Metal release from plates used in jaw fracture treatment. A pilot study. Int J Oral Maxillofac Surg 1989; 18: 311-314.

3.O'Connell J, Murphy C, Ikeagwuani O, Adley C, Kearns $G$. The fate of titanium miniplates and screws used in maxillofacial surgery: a 10 year retrospective study.Int $\mathrm{J}$ Oral Maxillofac Surg 2009; 38: 731-735.

4.Haraji A, Motamedi MH, Moharamnejad N. Causes and incidence of miniplate removal following Le Fort I osteotomy.Eplasty 2009; 12: 9: e45.

5.Widar F, Afshari M, Rasmusson L, Dahlin C, Kashani $\mathrm{H}$. Incidence and risk factors predisposing plate removal following orthognathic surgery. Oral Surg Oral Med Oral Pathol Oral Radiol 2017; 124: 231-239.

6. Falter B, Schepers S, Vrielinck L, Lambrichts I, Politis C. Plate removal following orthognathic surgery. Oral Surg Oral Med Oral Path Oral Radiol Endo 2011; 112: 737-743.

7. Kuhlefelt $M$, Laine $P$, Suominen-Taipale L, Ingman T, Lindqvist $\mathrm{C}$, et al. Risk factors contributing to symptomatic miniplate removal: a retrospective study of 153 bilateral sagittal split osteotomy patients. Int J Oral Maxillofal Surg 2010; 39: 430-435.

8.Theodossy $T$, Jackson $O$, Petrie A, Lloyd T. Risk factors contributing to symptomatic plate removal following sagittal split osteotomy. Int J Oral Maxillofal Surg 2006; 35: 598-601.

9.Little M, Langford RJ, Bhanji A, Farr D. Plate removal following orthognathic surgery. J Craniomaxillofac Surg 2015; 43: 1705-1709.

10.Gómez-Barrachina R, Montiel-Company JM, García-Sanz V, Almerich-Silla JM, Paredes-Gallardo V, et al. Titanium plate removal in orthognathic surgery: prevalence, causes and risk factors. A systematic literature review and meta-analysis. Int J Oral Maxillofac Surg 2020; 49: 770-778.

11.Jhass AK, Johnston DA, Gulati A, Anand R, Stoodley $P$, Sharma S. A scanning electron microscope characterisation of biofilm on failed craniofacial osteosynthesis miniplates. J Craniomaxillofac Surg 2014; 7: 372-378.

12.Sukegawa $S$, Kanno T, Manabe $Y$, Matsumoto $K$, Sukegawa-Takahashi $Y$, et al. Is the removal of osteosynthesis plates after orthognathic surgery necessary? Retrospective long-term follow-up study. Int J Oral Maxillofac Surg 2018; 47: 1581-1586.

13.Al-Moraissi EA, Al-Hendi EA. Are bicortical screw and plate osteosynthesis techniques equal in providing skeletal stability with the bilateral sagittal split osteotomy when used for mandibular advancement surgery? A systematic review and meta-analysis. Int J Oral Maxillofac Surg 2016; 45: 1195-1200.

14.Verweij JP, Houppermans PN, Mensink G, van Mer- 
kesteyn JP. Removal of bicortical screws and other osteosynthesis material that caused symptoms after bilateral sagittal split osteotomy: a retrospective study of 251 patients, and review of published papers. $\mathrm{Br} \mathrm{J}$ Oral Maxillofac Surg 2014; 52: 756-760.

15.Bouwman JP, Husak A, Putnam GD, Becking AG, Tuinzing $D B$. Screw fixation following bilateral sagittal ramus osteotomy for mandibular advancement complications in 700 consecutive cases. Br J Oral Maxillofac Surg 1995; 33: 2314.

16.Becelli R, Fini G, Renzi G, Giovannetti F, Roefaro E. Complications of bicortical screw fixation observed in 482 mandibular sagittal osteotomies. J Craniofac Surg 2004; 15: 64-68.

17.Lacey MS, Colcleugh RG. Infected screws in patients treated by mandibular sagittal split osteotomy. $\mathrm{J}$ Oral Maxillofac Surg 1995; 53: 510-513.

18. Rubio JC, Garcia-Alonso MC, Alonso C, Alobera M A, Clemente $\mathrm{C}$, et al. Determination of metallic traces in kidneys, livers, lungs and spleens of rats with metallic implants after a long implantation time. J Mater Sci: Mater Med 2008; 19: 369-375.

19.Sarmiento-González A, Encinar JR, Marchante-Gayón JM, Sanz-Medel A. Titanium levels in the organs and blood of rats with a titanium implant, in the absence of wear, as determined by double-focusing ICP-MS. Anal Bioanal Chem 2009; 393: 335-343. 